Western University

Scholarship@Western

Communication Sciences and Disorders

Publications

Communication Sciences and Disorders School

$7-1-2020$

\title{
Relationship of Head Circumference and Age in the Prediction of the Real-Ear-to-Coupler Difference (RECD)
}

\author{
Kelli M. Watts \\ Auburn University \\ Marlene Bagatto \\ The University of Western Ontario, bagatto@nca.uwo.ca \\ Sandra Clark-Lewis \\ Auburn University \\ Samantha Henderson \\ Auburn University \\ Susan Scollie \\ The University of Western Ontario
}

See next page for additional authors

Follow this and additional works at: https://ir.lib.uwo.ca/scsdpub

Part of the Communication Sciences and Disorders Commons

Citation of this paper:

Watts KM, Bagatto M, Clark-Lewis S, Henderson S, Scollie S, Blumsack J. Relationship of Head Circumference and Age in the Prediction of the Real-Ear-to-Coupler Difference (RECD). J Am Acad Audiol. 2020 Jul;31(7):496-505. doi: 10.3766/jaaa.19017. Epub 2020 Sep 2. PMID: 32119819. 


\section{Authors}

Kelli M. Watts, Marlene Bagatto, Sandra Clark-Lewis, Samantha Henderson, Susan Scollie, and Judith Blumsack 


\title{
Relationship of Head Circumference and Age in the Prediction of the Real-Ear-to-Coupler Difference (RECD)
}

\author{
Kelli M. Watts ${ }^{1}$ Marlene Bagatto ${ }^{2}$ Sandra Clark-Lewis ${ }^{1}$ Samantha Henderson ${ }^{1}$ Susan Scollie ${ }^{2}$ \\ Judith Blumsack ${ }^{1}$
}

${ }^{1}$ Auburn University, Auburn, AL

2 Western University, Ontario, Canada

Address for correspondence Kelli M. Watts, Auburn University, Auburn, AL 36849 (e-mail: mcdowkm@auburn.edu).

J Am Acad Audiol 2020;31:496-505.

\begin{abstract}
Background Pediatric hearing instrument fitting is optimally performed with individually obtained real-ear-to-coupler difference (RECD) measurements. If these measurements cannot be obtained, predicted values based on age are used. Recent evidence obtained from children aged $3-11$ years suggests that head circumference $(\mathrm{HC})$ may be a viable alternative or addition to age for use in RECD prediction.

Purpose The purpose of the present study was to determine if $\mathrm{HC}$ can be used to predict RECDs in infants, children, and adults.

Research Design A correlational design was used. HC and RECD values were measured in all participants.

Study Sample Participants were 278 North American infants and children (136 males and 142 females) aged 1.6 months to 11 years and 109 adults (42 males and 67 females) aged 18 years to 83 years.

Data Collection and Analysis After otoscopic inspection and immittance measurements were performed to assess candidacy for inclusion in the study, $\mathrm{HC}$ was measured twice for all participants and a single RECD measure was obtained for each participant at twelve frequencies ( 250 through $12500 \mathrm{~Hz}$ ). The reliability of $\mathrm{HC}$ measurements was assessed with an intraclass correlation analysis. Linear regression analyses were performed with age and $\mathrm{HC}$ as predictor variables and RECDs as the dependent

\section{Key words}

- head circumference

- hearing aids

- hearing instrument fitting

- RECD

variable.

Results Analysis indicated good reliability of the $\mathrm{HC}$ measurement. The relationships between RECD and HC were comparable with the relationships between RECD and age. Combining $\mathrm{HC}$ and age did not improve predictive accuracy.

Conclusions $\mathrm{HC}$ can be used in children and adults as an alternative metric in the prediction of RECDs when individual RECDs cannot be obtained.
\end{abstract}

\section{Introduction}

Real-ear-to-coupler difference (RECD) values play a critical role in hearing aid fitting to infants and young children. The RECD is simply the difference in decibels between the level of a broadband signal recorded in an individual's ear canal and the same sound measured in a $2 \mathrm{cc}$ coupler. The RECD accounts for the differences in acoustics between the metal coupler (which was designed to mimic the size of an adult ear canal) and an individual's ear. RECDs are used to calculate the sound pressure level in the ear canal for the purpose of calculating amplification targets. They also are used for hearing aid verification to ensure safe and accurate output
Copyright $\odot 2020$ by the

American Academy of Audiology. All rights reserved. Thieme

Medical Publishers, Inc., 333

Seventh Avenue, New York, NY

10001, USA. Tel: +1(212) 760-0888.
DOI https://doi.org/ 10.3766/jaaa.19017. ISSN 1050-0545. 
levels that provide appropriate access to auditory input. Specifically, the RECD is used to support coupler-based, or simulated, real-ear verification methods. Variability of RECD values among infants and children of the same age is high, and RECD values change with ear canal growth (Feigin et al ${ }^{14}$; Bagatto et $\mathrm{al}^{4}$; Bingham et $\mathrm{al}^{7}$ ). Accordingly, the American Academy of Audiology's clinical practice guidelines recommend the use of individual RECD measurements in the pediatric hearing aid fitting process whenever possible $\left(\mathrm{AAA}^{1}\right)$.

Recent evidence suggests that the clinical use of RECD measurement has increased overtime (McCreery et al ${ }^{19}$; Moodie et $\mathrm{al}^{21}$ ). However, circumstances sometimes prohibit individual RECD measurement in the pediatric population (Moodie et $\mathrm{al}^{21}$ ). For example, in some clinics, real-ear measurement equipment may not be available (Moodie et $\mathrm{al}^{21}$ ). In addition, excessive cerumen or high patient activity levels can preclude measurement (Moodie et $\mathrm{al}^{21}$ ). If direct RECD measurement is not possible, age-based predicted RECDs are available in commercially available software and real-ear measurement systems (Bagatto et $\mathrm{al}^{4}$ ). Even with optimal probe microphone placement, individual RECD values can vary by as much as $\pm 5.6 \mathrm{~dB}$ at $500 \mathrm{~Hz}$ to $\pm 10.9 \mathrm{~dB}$ at $6000 \mathrm{~Hz}$ when compared with age-based predicted RECDs (Bagatto et $\mathrm{al}^{5}$ ). This error can be expected to be even greater for children who have growth retardation (Blumsack et $\mathrm{al}^{8}$ ) or other developmental anomalies.

Recent research indicates that head circumference (HC)based RECD predictions might provide a useful alternative or supplement to age-based RECD predictions in settings where stunted growth is common (Blumsack et $\mathrm{al}^{9}$ ) and in atypically developing children. In developing countries, the prevalence of stunted growth can range from $38 \%$ to $45 \%$ (de Onis et $\mathrm{al}^{12}$ ) and access to probe-microphone equipment for measuring RECDs may be very limited. At present, data relating HC to RECD values are available only for typically developing children aged 3 to 11 years $\left(\right.$ Blumsack et $\mathrm{al}^{9}$ ). These data indicate that when individual RECD measurements cannot be obtained, $\mathrm{HC}$ can be considered as a reliable alternative equivalent to age as a metric for RECD prediction. It is necessary to determine if the relationship between RECDs and HC is also present in children younger than 3 years. As recommended by the Joint Committee on Infant Hearing $\left(\mathrm{JClH}^{15}\right)$, hearing aid fittings often occur in the first few months of life in many areas of the world; therefore, expanding the investigation to include infant and toddler populations may support further clinical application. The purpose of the present study was to expand on the work by Blumsack et $\mathrm{al}^{9}$ by including more participants and a larger variety of ages and to investigate the relationship between HC and age on RECD values in a sample of infants, children, and adults.

\section{Method}

\section{Participants}

Participants were 278 North Americans: 87 infants with an average age of 20.1 months (range $=1.6-35$ months), 191 children with an average age of 6.0 years ( range $=3.0-11.92$ years), and 109 adults with an average age of 53.75 years (range $=18.0-83.0$ years). The gender breakdown for each age-group is given as follows: infants: 45 males, 41 females, and 1 unknown; children: 90 males and 101 females; and adults: 42 males and 67 females. Participants were eligible to be included in the study if they were observed through otoscopic examination to have at least one ear canal free of debris with an intact tympanic membrane, no detectable middle ear fluid as confirmed by immittance measurement, and no noted craniofacial anomalies. Participants were recruited through Auburn University in Alabama, United States, and the National Centre for Audiology at Western University in London, Canada. The study protocol was approved by ethics review boards at both Auburn and Western universities. Participants were recruited using flyers posted on social media and at data collection sites, which included speech and hearing clinics, day care centers, churches, and through an existing research participant pool at the National Centre for Audiology. All included children were examined at the Auburn University; all adults were assessed at Western University.

\section{Procedures}

After informed consent was obtained from the care-giver/participant as appropriate as per the approved protocol, a cursory otoscopic examination of both ears was performed. The clearest ear was selected as the test ear for the RECD measurement. If both ear canals had cerumen judged to impede proper probetube placement, removal was completed using a Bionix ${ }^{\mathrm{TM}}$ (Bionix Development Corporation, Toledo, $\mathrm{OH}$ ) lighted curette, and the clearest ear was selected as the test ear. Immittance measurement was conducted in the test ear. If the immittance results in the initial test ear were abnormal (see Appendix A), immittance testing was conducted in the other ear, if otoscopy revealed a clear ear canal for RECD measurement. If the criteria were not met in either ear, no further testing was conducted, and information regarding medical follow-up was given to the consenting adult.

RECD measurements were obtained using an Audioscan ${ }^{\circledR}$ (Dorchester, Ontario, Canada) Verifit ${ }^{\circledR} 2$ (software versions: Auburn: 4.8; Western: 4.12.5) and referenced to the HA-1 coupler (ANSI S3.46 2013). Calibration of the real-ear system was performed as per the manufacturer's instructions $\left(\right.$ AudioScan $^{2}$ ). Coupler measures were obtained using the HA-4 coupler and RECD transducer within Verifit ${ }^{\circledR} 2$. For the real-ear portion of the RECD, the probe tube was marked to indicate the appropriate insertion depth based on the participant's age and gender (Bagatto et $\mathrm{al}^{4}$ ). Using the marker as a reference, the tube was inserted so that based on the data from average, normally developing ears, the tip of the tube should have been within 3 to $5 \mathrm{~mm}$ of the tympanic membrane (Bagatto et $\mathrm{al}^{4}$; Bagatto et $\mathrm{al}^{6}$ ). An appropriately sized foam eartip (either 3M E-A-RLink 3A [yellow] or 3B [beige]) connected to the Verifit ${ }^{\circledR} 2$ RECD transducer was introduced into the participant's ear canal. Sound was delivered through the foam eartip to measure the individual real-ear response. Because a majority of participants did not have custom earmolds, RECD measurements with an earmold were not 
considered in this study. To ensure that the RECD values were appropriate at all frequencies, adjustments were made in accordance with the Verifit ${ }^{\circledR}$ User's Guide 4.2. If the RECD curve deviated more than $10 \mathrm{~dB}$ from the average in the low frequencies, the foam tip was re-inserted deeper or was increased in size and then re-inserted to improve the seal. If the RECD curve deviated more than $10 \mathrm{~dB}$ from the average in the 4-6 $\mathrm{kHz}$ region, the probe was removed and inspected for cerumen or other blockage. If the probe tube was clear, it was re-inserted and the measurement was completed. If the probe tube was blocked or misshapen, a new probe tube was inserted into the ear canal and used to complete the measurement.

$\mathrm{HC}$ was measured with a Pedia-Pal ${ }^{\mathrm{TM}} \mathrm{HC}$ measuring tape or other flexible, nonstretchable measuring tape with a centimeter scale. The measuring tape was placed over the most prominent part of the back of the head, positioned around the head above the ears and slightly above the eyebrows. The tape was held snugly in this position, and the HC was recorded to the nearest tenth of a centimeter $\left(\mathrm{CDCP}^{11}\right)$. The tape was removed, and a second HC measurement was obtained using the same method.

\section{Data Cleaning}

Before the regression analyses, the data were cleaned to account for typical measurement errors that occur in the RECD measurement. Errors in measured RECD values due to procedural imperfections occur in two forms: slit leak venting and shallow probe-tube placement (Bagatto et $\mathrm{al}^{4}$ ). These are likely to occur in both the pediatric and adult clinical population. Given these data were collected using a routine clinical procedure (Moodie et $\mathrm{al}^{21}$ ), both types of errors were noted in the RECD values and were adjusted before the regression analyses. To account for slit leak venting, values at 250,500 , and $750 \mathrm{~Hz}$ were coded as missing if the measured RECD value was $-5 \mathrm{~dB}$ or less. This occurred 20 times at $250 \mathrm{~Hz}$, two times at $500 \mathrm{~Hz}$, and not at all at $750 \mathrm{~Hz}$. To account for shallow probe-tube placement, RECD values were inspected for early roll-off and coded as missing at some high frequencies if this occurred. Pediatric data were inspected differently from adult data because of the difference in the resonant properties of the ear canal with age. For the pediatric data, if the RECD value at $6000 \mathrm{~Hz}$ was less than the value at $4000 \mathrm{~Hz}$, values from $6000 \mathrm{~Hz}$ and above were coded as missing and not included in the regression analyses. Data were coded as missing for 22 cases in the combined pediatric data ( 6 infants younger than 3 years; 16 children aged 3 to 11 years). For the adult data, if the RECD value at $3000 \mathrm{~Hz}$ was less than the value at $2000 \mathrm{~Hz}$, values from $3000 \mathrm{~Hz}$ and above were coded as missing. Data were coded as missing for 24 adult cases.

\section{Planned Analysis}

Planned statistical analyses included the use of linear regression to assess relationships among HC, age, and RECDs at each of twelve auditory frequencies. Analysis of variances (ANOVAs) with paired comparisons were used to detect possible differences among $\mathrm{HC}$ and age and the combination of these two variables in their relative utility for predicting RECDs.

\section{Results}

The present study investigated the extent to which RECD values can be predicted by HC and/or age. It expands previous work used HC to predict RECDs (Blumsack et $\mathrm{al}^{9}$ ). The reliability of the repeated $\mathrm{HC}$ measurements was assessed using intraclass correlation. To evaluate the relationship between HC and/or age on RECD values, linear regression analyses were performed using RECD values per frequency as the dependent variable with three separate independent variables: (a) HC, (b) logarithm of age (days), and (c) backward regression with HC and logarithm of age (days). Statistically, the logarithmic regression analysis provided significantly better fits to the data than linear regression analysis; thus, age was converted to logarithm of age to normalize the residuals.

Before presenting the intraclass correlations, it is of importance to view the overall mean and variance data for our RECD measures. - Figure 1 shows the average comparisons. The average RECDs for 1- to 12-month-olds were compared with the 95\% confidence intervals for DSL v5.0 predicted RECDs for 4-month-olds. These ages were chosen because this is the age-group with the most RECD variability (Bagatto et $\mathrm{al}^{4}$ ). The average RECDs for the current study fall within the confidence interval for the DSL-predicted RECDs for 4-month-olds.

In the combined sample of pediatric and adult participants, the mean HC was $52.58 \mathrm{~cm}$ (range $=39.30-62.35 \mathrm{~cm}$ ). Linear regression analyses were performed on the combined pediatric and adult RECD data at 12 frequencies, with the logarithm of age (days) and $\mathrm{HC}(\mathrm{cm})$ as independent variables conducted separately and combined in a backward regression. Significance values for the regression estimates are presented for each frequency in - Tables 1-3.

The regression coefficients and $r^{2}$ values for each frequency for the RECD data are also found in - Tables 1-3. The $r^{2}$ values shown in the tables indicate a weak to modest association between the RECD values and HC or age. When HC is considered, $r^{2}$ values range from 0.047 at $10000 \mathrm{~Hz}$ to 0.462 at $750 \mathrm{~Hz}$. For the logarithm of age, $r^{2}$ range from 0.028 at $12500 \mathrm{~Hz}$ to 0.469 at $750 \mathrm{~Hz}$. When $\mathrm{HC}$ and age are combined, the $r^{2}$ values are not enhanced and range from 0.054 at $12500 \mathrm{~Hz}$ to 0.493 at $750 \mathrm{~Hz}$.

From the regression data in $\mathbf{- T a b l e s} \mathbf{1 - 3}$, different equations at each frequency were developed to predict RECDs based on HC, logarithm of age, and logarithm of age and HC combined. A visual representation of the raw data along with the linear equation for predicting RECDs based on HC and logarithm of age was developed. Scatterplots with trend lines for RECDs using HC and logarithm of age at 500, 1000, 2000, and $4000 \mathrm{~Hz}$ are provided in Appendix B.

- Tables 1 and $\mathbf{2}$ use the simple linear equation formula, $y=m x+b$, where $m$ is the slope and $b$ is the constant or $y$ intercept, for each RECD frequency. For - Tables 1 and 2, the different slopes and constants for each frequency can be put into the equation. The $y$ variable for - Table 1 is the RECD, and 


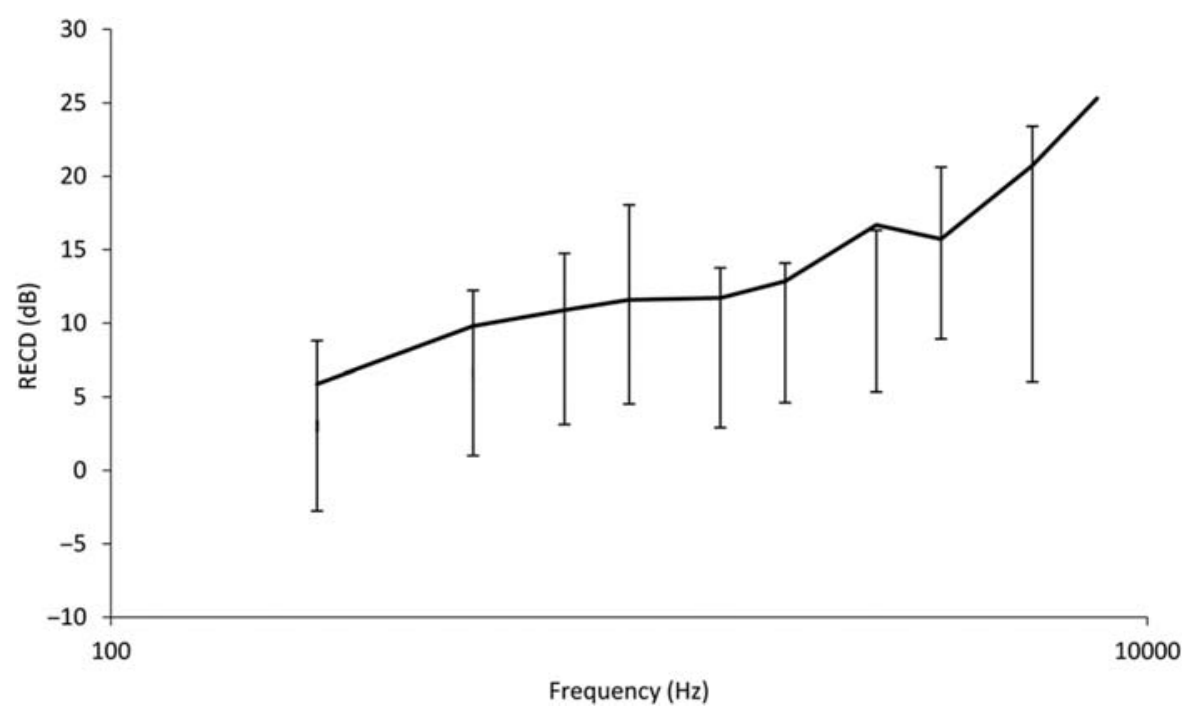

Fig. 1 Average Comparison for infants aged 1-12 months.

$x$ variable is the logarithm of age in days. Similarly, the $y$ variable for $\boldsymbol{- T a b l e} \mathbf{2}$ is the RECD, and the $x$ variable is the HC. If an individual's RECD values needed to be calculated and age or HC are readily available, then these equations could be used to predict RECD values at each frequency. For example, if a 563-day-old child with a HC of $46.4 \mathrm{~cm}$ needed to have RECDs completed, then these values could be inserted into the formulas based on the values in - Tables $\mathbf{1}$ and $\mathbf{2}$ for each frequency. The age-based predicted $1000-\mathrm{Hz}$ RECD value would equal $10.1 \mathrm{~dB}$, and the HC-based $1000-\mathrm{Hz}$ RECD value would equal $10.7 \mathrm{~dB}$. To calculate the other frequency RECD values, one would have to use different $y$ and $b$ values in the formula to calculate each frequency.

The difference, in $\mathrm{dB}$, between the measured and predicted RECD value (using the regression coefficients shown in the tables) was calculated at each frequency for each participant. The mean (unsigned) absolute error values associated with the RECD predictions based on each analysis strategy are shown in - Table $\mathbf{4}$, along with the $95 \%$ confidence interval and the standard deviation (SD) as a function of frequency. Results showed that when HC was used to predict the RECD value, the average error ranged from a low of $1.51 \mathrm{~dB}$ at $2000 \mathrm{~Hz}$ to a high of $5.53 \mathrm{~dB}$ at $12500 \mathrm{~Hz}$. When age is used to predict the RECD value, the average error ranged from a low of $1.42 \mathrm{~dB}$ to a high of $5.64 \mathrm{~dB}$ at 2000 and $12500 \mathrm{~Hz}$, respectively. When $\mathrm{HC}$ and age are combined, prediction errors ranged from a low of $1.47 \mathrm{~dB}$ to a high of $5.51 \mathrm{~dB}$ at 2000 and $12500 \mathrm{~Hz}$. By examining the 95\% confidence intervals in - Table 4 , it can be seen that HC and age predict the RECD value equally well and when combined, the predictive accuracy does not improve.

\section{ANOVA and Paired Comparison}

Sphericity could not be assumed in the population for any one of the 12 analyses (Muchly's test of sphericity $p \leq 0.05$ ). Therefore, multivariate results (Wilks' lambda-associated $F$ values) are reported for all omnibus tests. Paired sample were used for pairwise follow-up comparison. - Table 5 displays statistics for the omnibus test as well as for follow-up pairwise comparisons. The Bonferroni (omnibus test alpha divided by the number of pairwise comparisons) is used to control for Type I error across follow-up analyses per Hertz level $(0.05 / 3=0.017)$.

Results were somewhat mixed. Omnibus test statistical significance was reached at all levels except 4000,10000, and $12500 \mathrm{~Hz}$. Effect sizes, for most analyses, were medium or approaching medium (see Cohen ${ }^{10}$ ). At 4000, 8000, 10000, and $12500 \mathrm{~Hz}$, effect sizes were small. After controlling for Type I error, four of the 36 pairwise comparisons reached statistical significance.

HC as a predictor alone was statistically significantly different from age and both $\mathrm{HC}$ and logarithm of age combined at levels 250,1000 , and $2000 \mathrm{~Hz}$. At each of these frequencies, the mean predicted RECDs from HC measurements were greater than the mean RECD for HC and logarithm of age combined. Age as a predictor alone was statistically significantly different from $\mathrm{HC}$ and logarithm of age together at $500 \mathrm{~Hz}$, with the mean for age greater than the mean for both age and HC together.

\section{Discussion}

The purpose of this study was to explore the relationship between RECD and HC across the life span. The key findings of this study are:

- In children and adults, HC is comparable with age as a metric for RECD prediction. This is consistent with the previous work by Blumsack et al. ${ }^{9}$ Analyses of the present results indicated no advantage in predicting RECDs by combining $\mathrm{HC}$ and age.

- In children aged 1 to 12 months, RECD measurements using foam eartips were consistent with available agebased predictions (Bagatto et $\mathrm{al}^{4}$ ).

At the outset, it is important to emphasize that measurement of a patient's individual RECD is recommended (Bagatto et $\mathrm{al}^{4}$; $\mathrm{AAA}^{1}$; McCreery et $\mathrm{al}^{18}$ ). Individual RECD values for children who are of the same age can vary from 15 to $20 \mathrm{~dB}$ in children with intact tympanic membranes or more in children 

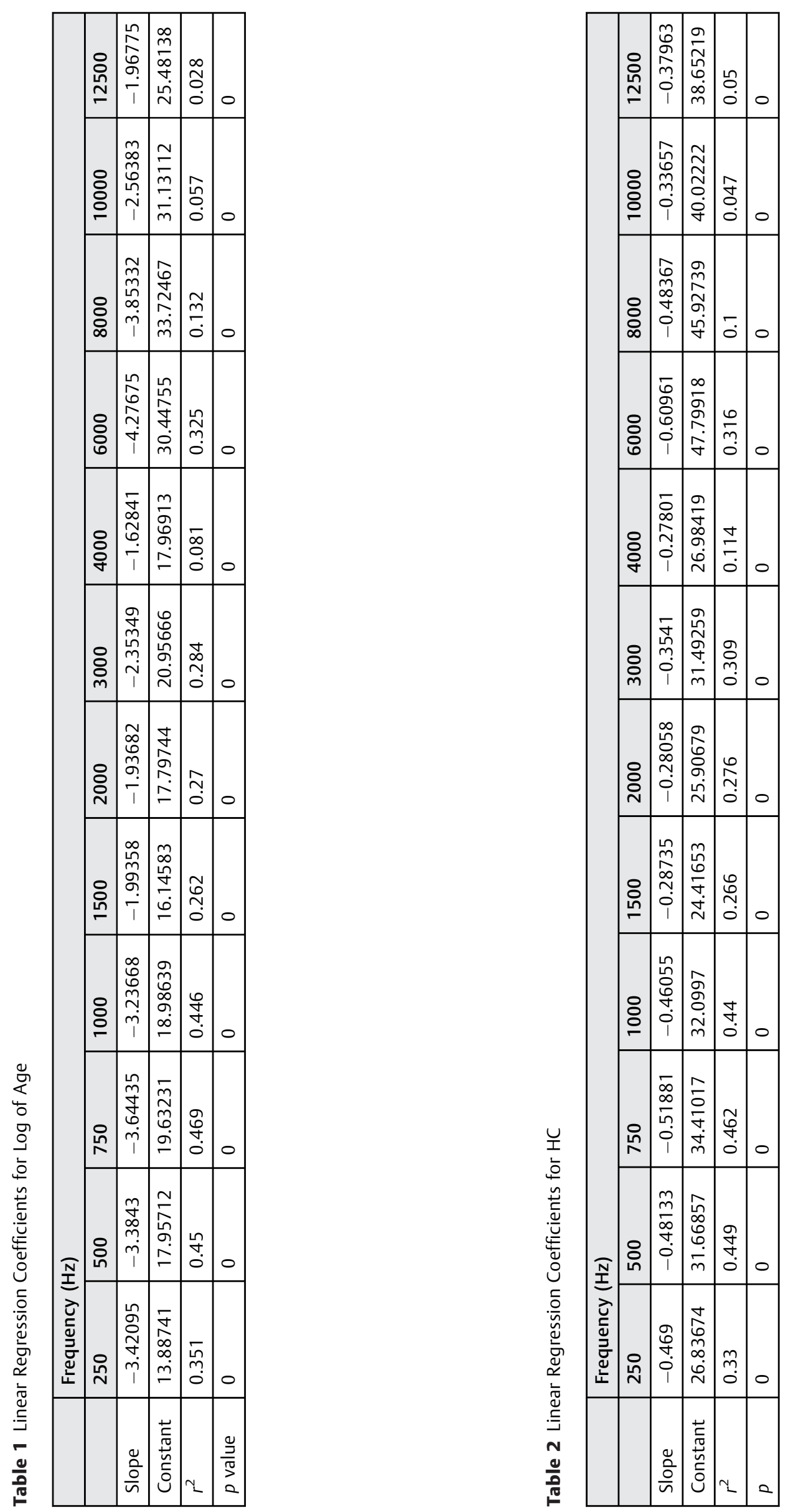


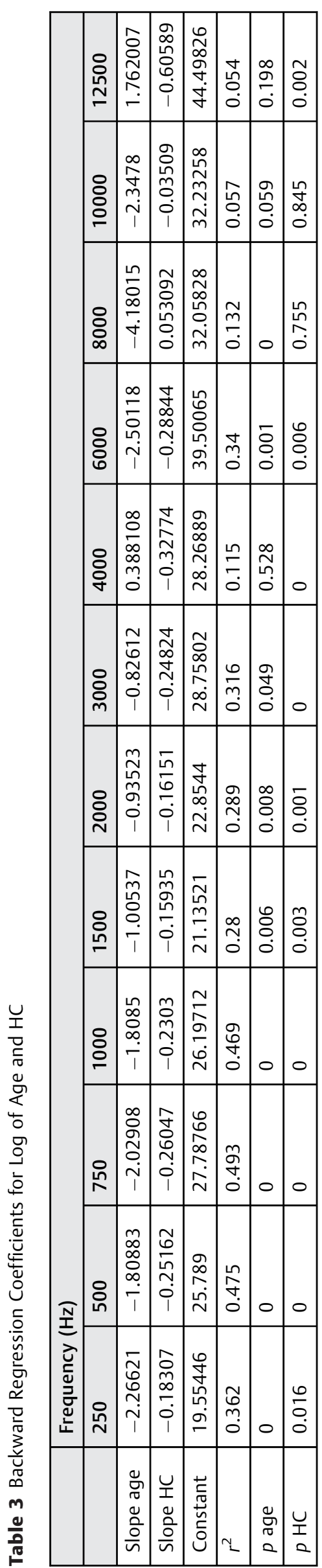

with tympanic membrane perforations, patent tympanostomy tubes, middle-ear dysfunction, or other ear canal malformations (Martin et $\mathrm{al}^{17}$; Bagatto et $\mathrm{al}^{5}$; McCreery et $\mathrm{al}^{18}$ ). However, some circumstances such as excessive cerumen or high patient activity (Moodie et $\mathrm{al}^{21}$ ) may preclude obtaining individual RECD values. Individual RECD measurement also may be precluded because equipment is not available or clinicians may have inadequate training on the use of the equipment. When individual RECD values cannot be measured, RECD predictions based on age are available in applications of prescriptive software (e.g., Scollie et $\mathrm{al}^{25}$ ). The most recently available RECD predictions provide values for ages to the nearest month through age 5 years and to the nearest year, age 6 years through 12 years, for both foam tip and earmold coupling (Bagatto et $\mathrm{al}^{3,4}$ ).

The current study revealed that HC could be used as an alternative metric to age to predict RECD values measured with a foam tip. However, children fit with amplification typically use a custom earmold to direct sound to the ear. Because most clinicians consider measuring RECD to be part of hearing aid verification, it is typically measured with a child's personal earmold (Moodie et $\mathrm{al}^{21}$ ). This creates a mismatch between the RECD that is used to estimate hearing aid output in the coupler and the RECD used to assess the child's hearing thresholds. Earmold tubing diameter and length can affect hearing aid output in the 2000- to 3000$\mathrm{Hz}$ range. RECDs measured using an earmold with a large vent or a loosely fitting earmold can result in large negative RECD values. Conversely, very tight-fitting earmolds may cause the probe microphone tube to be crimped, preventing the individual RECD from being measured altogether. Foam tip to earmold correction values have been developed and implemented into some fitting software (Moodie et $\mathrm{al}^{20}$ ). These correction values are applied when a foam tip RECD has been measured for assessment and an earmold RECD is needed for verification. These values do not depend on age and may be more accurate than applying the current earmold RECD prediction values (Bagatto et $\mathrm{al}^{3}$ ). Further investigation is needed to determine if HC could accurately predict RECD values when RECDs are measured with personal earmolds.

As previously stated, using age-based RECD predictions for typically developing North American infants and children is not without error. Studies indicate that when individually measured RECDs are compared with available age-based norms, values vary as widely as $\pm 5.6 \mathrm{~dB}$ at $500 \mathrm{~Hz}$ to $\pm 10.9 \mathrm{~dB}$ at $6000 \mathrm{~Hz}$ for infants and children (Bagatto et $\mathrm{al}^{4}$ ). The error between age-based predictions and individual RECD values is even larger in undernourished children (Blumsack et $\mathrm{al}^{8}$ ). Thus, alternatives to using age as a metric for RECD prediction warrant investigation. Blumsack et $\mathrm{al}^{9}$ considered height, weight, and $\mathrm{HC}$ as possible metrics for predicting RECD values. They found that although height and weight could predict RECDs at some frequencies, $\mathrm{HC}$ was the only variable that could predict RECD values at 500 through $6000 \mathrm{~Hz}$ for both ears.

In North America (for typically developing infants and children), RECD predictions based on age would yield results similar to predictions based on HC. Therefore, measures of HC would not be necessary. However, $\mathrm{HC}$ is used worldwide as a 
Table 4 Mean RECD Prediction Error Values for Age, HC, and Age/HC Combined

\begin{tabular}{|c|c|c|c|c|c|c|c|c|c|c|c|c|c|c|c|c|c|c|}
\hline & \multicolumn{18}{|c|}{ Frequency $(\mathrm{Hz})$} \\
\hline & \multicolumn{3}{|l|}{250} & \multicolumn{3}{|l|}{500} & \multicolumn{3}{|l|}{750} & \multicolumn{3}{|l|}{1000} & \multicolumn{3}{|c|}{1500} & \multicolumn{3}{|c|}{2000} \\
\hline & Age & $\mathrm{HC}$ & Both & Age & $\mathrm{HC}$ & Both & Age & $\mathrm{HC}$ & Both & Age & $\mathrm{HC}$ & Both & Age & $\mathrm{HC}$ & Both & Age & $\mathrm{HC}$ & Both \\
\hline Average $(\mathrm{dB})$ & 2.2 & 2.2 & 2.2 & 1.8 & 1.8 & 1.7 & 1.9 & 1.9 & 1.8 & 1.7 & 1.8 & 1.7 & 1.6 & 1.6 & 1.6 & 1.5 & 1.5 & 1.5 \\
\hline SD & 1.7 & 1.7 & 1.7 & 1.4 & 1.4 & 1.4 & 1.4 & 1.4 & 1.4 & 1.3 & 1.3 & 1.4 & 1.2 & 1.2 & 1.2 & 1.2 & 1.2 & 1.3 \\
\hline \multirow[t]{4}{*}{$\begin{array}{l}\text { Confidence } \\
\text { interval }( \pm)\end{array}$} & 3.4 & 3.4 & 3.3 & 2.7 & 2.8 & 2.7 & 2.8 & 2.9 & 2.8 & 2.6 & 2.6 & 2.6 & 2.5 & 2.4 & 2.4 & 2.5 & 2.3 & 2.4 \\
\hline & \multicolumn{18}{|c|}{ Frequency $(\mathrm{Hz})$} \\
\hline & \multicolumn{3}{|c|}{3000} & \multicolumn{3}{|c|}{4000} & \multicolumn{3}{|c|}{6000} & \multicolumn{3}{|l|}{8000} & \multicolumn{3}{|c|}{10000} & \multicolumn{3}{|c|}{12500} \\
\hline & Age & $\mathrm{HC}$ & Both & Age & $\mathrm{HC}$ & Both & Age & $\mathrm{HC}$ & Both & Age & $\mathrm{HC}$ & Both & Age & $\mathrm{HC}$ & Both & Age & $\mathrm{HC}$ & Both \\
\hline Average $(\mathrm{dB})$ & 1.7 & 1.7 & 1.7 & 2.5 & 2.4 & 2.4 & 2.8 & 2.8 & 2.8 & 4.7 & 4.8 & 4.7 & 5.2 & 5.2 & 5.2 & 5.6 & 5.5 & 5.5 \\
\hline SD & 1.4 & 1.4 & 1.4 & 2.1 & 2.0 & 2.0 & 2.5 & 2.5 & 2.5 & 3.7 & 3.8 & 3.7 & 3.6 & 3.7 & 3.6 & 4.3 & 4.3 & 4.3 \\
\hline $\begin{array}{l}\text { Confidence } \\
\text { interval }( \pm)\end{array}$ & 2.8 & 2.7 & 2.7 & 4.2 & 4.1 & 4.1 & 5.0 & 5.0 & 5.0 & 7.5 & 7.6 & 7.5 & 7.3 & 7.4 & 7.3 & 8.6 & 8.6 & 8.5 \\
\hline
\end{tabular}

Table 5 Pairwise Comparisons

\begin{tabular}{|c|c|c|c|c|c|c|c|c|c|c|c|c|}
\hline & \multicolumn{12}{|c|}{ Frequency $(\mathrm{Hz})$} \\
\hline & 250 & 500 & 750 & 1000 & 1500 & 2000 & 3000 & 4000 & 6000 & 8000 & 10000 & 12500 \\
\hline $\begin{array}{l}\text { Omnibus } \\
\text { test } F_{(\mathrm{df})}, \\
p \text { value }\end{array}$ & $\begin{array}{l}10.86 \\
(2,365) \\
<0.001^{*}\end{array}$ & $\begin{array}{l}11.78 \\
(2,383) \\
<0.001^{*}\end{array}$ & $\begin{array}{l}11.95 \\
(2,385) \\
<0.001^{*}\end{array}$ & $\begin{array}{l}14.86 \\
(2,385), \\
<0.001^{*}\end{array}$ & $\begin{array}{l}6.62 \\
(2,385), \\
0.001^{*}\end{array}$ & $\begin{array}{l}10.87 \\
(2,385) \\
<0.001^{*}\end{array}$ & $\begin{array}{l}8.23 \\
(2,361), \\
<0.001^{*}\end{array}$ & $\begin{array}{l}1.87 \\
(2,361) \\
0.155\end{array}$ & $\begin{array}{l}9.03 \\
(2,337), \\
<0.001^{*}\end{array}$ & $\begin{array}{l}3.26 \\
(2,337), \\
0.039^{*}\end{array}$ & $\begin{array}{l}0.701 \\
(2,337) \text {, } \\
0.497\end{array}$ & $\begin{array}{l}2.88 \\
(2,337), \\
0.058\end{array}$ \\
\hline $\begin{array}{l}\text { Omnibus } \\
\text { effect size, } \\
\text { eta squared }\end{array}$ & 0.056 & 0.058 & 0.058 & 0.072 & 0.033 & 0.053 & 0.044 & 0.010 & 0.051 & 0.019 & 0.004 & 0.017 \\
\hline $\begin{array}{l}\text { Pair } 1: \log \text { of } \\
\text { age and } \\
\text { HC } t_{(\mathrm{df})} \\
p \text { value }\end{array}$ & $\begin{array}{l}-1.74 \\
(366), \\
0.083\end{array}$ & $\begin{array}{l}0.49 \\
(384), \\
0.624\end{array}$ & $\begin{array}{l}0.066 \\
(386), \\
0.948\end{array}$ & $\begin{array}{l}-0.484 \\
(386), \\
0.628\end{array}$ & $\begin{array}{l}-0.487 \\
(386), \\
0.626\end{array}$ & $\begin{array}{l}-1.22 \\
(386), \\
0.225\end{array}$ & $\begin{array}{l}0.662 \\
(362), \\
0.508\end{array}$ & $\begin{array}{l}1.55 \\
(362), \\
0.122\end{array}$ & $\begin{array}{l}-0.56 \\
(338), \\
0.576\end{array}$ & $\begin{array}{l}-1.43 \\
(338), \\
0.154\end{array}$ & $\begin{array}{l}-0.556 \\
(338) \\
0.579\end{array}$ & $\begin{array}{l}2.19 \\
(338), \\
0.029\end{array}$ \\
\hline $\begin{array}{l}\text { Pair 2: } \log \text { of } \\
\text { age vs. HC and } \\
\text { log of age } \\
\text { together } \\
t_{(\mathrm{df})}, p \text { value }\end{array}$ & $\begin{array}{l}0.58 \\
(366), \\
0.562\end{array}$ & $\begin{array}{l}2.52 \\
(384), \\
0.012^{* \dagger}\end{array}$ & $\begin{array}{l}2.27 \\
(386), \\
0.024\end{array}$ & $\begin{array}{l}2.13 \\
(386), \\
0.034\end{array}$ & $\begin{array}{l}0.857 \\
(386), \\
0.392\end{array}$ & $\begin{array}{l}0.455 \\
(386), \\
0.649\end{array}$ & $\begin{array}{l}1.65 \\
(362), \\
0.100\end{array}$ & $\begin{array}{l}1.43 \\
(362), \\
0.155\end{array}$ & $\begin{array}{l}1.51 \\
(338), \\
0.251\end{array}$ & $\begin{array}{l}-0.258 \\
(338) \\
0.797\end{array}$ & $\begin{array}{l}-0.017 \\
(338), \\
0.987\end{array}$ & $\begin{array}{l}1.76 \\
(338), \\
0.08\end{array}$ \\
\hline $\begin{array}{l}\text { Pair } 3: \mathrm{HC} \\
\text { vs. } \mathrm{HC} \text { and } \\
\text { log of age } \\
\text { together } \\
t_{(\mathrm{df})}, p \text { value }\end{array}$ & $\begin{array}{l}2.90 \\
(366), \\
0.004^{* \dagger}\end{array}$ & $\begin{array}{l}1.61 \\
(384), \\
0.108\end{array}$ & $\begin{array}{l}1.97 \\
(386), \\
0.049\end{array}$ & $\begin{array}{l}2.76 \\
(386), \\
0.006^{* \dagger}\end{array}$ & $\begin{array}{l}1.87 \\
(386), \\
0.063\end{array}$ & $\begin{array}{l}2.97 \\
(386), \\
0.003^{* \dagger}\end{array}$ & $\begin{array}{l}1.53 \\
(362), \\
0.128\end{array}$ & $\begin{array}{l}0.565 \\
(362), \\
0.572\end{array}$ & $\begin{array}{l}1.84 \\
(338), \\
0.066\end{array}$ & $\begin{array}{l}1.31 \\
(338), \\
0.194\end{array}$ & $\begin{array}{l}0.606 \\
(338), \\
0.545\end{array}$ & $\begin{array}{l}0.715 \\
(338), \\
0.475\end{array}$ \\
\hline
\end{tabular}

*Indicates statistical significance.

${ }^{\dagger}$ Pairwise comparison alpha $=0.017$ based using Bonferroni test $(0.05 / 3)$.

growth measurement (de Onis et $\mathrm{al}^{13}$ ). HC can be measured easily, inexpensively, and reliably. In developing countries where atypical physical development is more common (de Onis et $\mathrm{al}^{12}$ ), HC-based RECD predictions may have value for pediatric hearing assessment and hearing aid fitting. Future research studying individuals with nutritionally related stunted growth, constitutional growth retardation, premature birth, or developmental anomalies would be useful to determine if in such individuals HC-based RECD predictions could be a more accurate alternative to predictions based on age.

\section{Summary and Conclusions}

This work re-examinedHC as an alternative metric for predicting RECD values in children and expanded the work to determine if HC could reliably predict RECDs in infants. HC was measured and applied in regression anal- yses alone and in combination with age to determine its predictive accuracy for RECD values across frequency. The measurement and use of a patient's individual RECD remain the best clinical practice. However, when the RECD cannot be measured, either $\mathrm{HC}$ or age can be considered as a viable metric for RECD prediction in typically developing North American infants, children, and adults. Further research is necessary to determine if the observed relationship between RECD and HC can be seen when patients' personal earmolds are used or if HCbased predictions generalize to populations with prematurity, nutritionally related growth retardation, constitutional growth retardation, and/or other developmental anomalies. Other anthropomorphic measurements, such as pinna-to-pinna measurements, could also be investigated to determine if they could be a viable alternative to age for predicting RECD values. 


\section{Abbreviations}

HC head circumference

RECD real-ear-to-coupler difference

SD standard deviation

\section{Notes}

Presented as a podium presentation at the World Congress of Audiology, Vancouver, British Columbia, Canada, September 21, 2016; presented as a poster at the 7th Annual International Pediatric Audiology Conference, Atlanta, GA, October 4, 2016; and presented at the fall meeting of the West Virginia Audiology Association, Pipestem, WV, September 29-30, 2017.

\section{Funding}

This research was supported by an AU-sponsored program fund (242398 GN RESOUND).

\section{Conflict of Interest}

None declared.

\section{Acknowledgments}

The authors wish to acknowledge grant support for this research provided to Auburn University by GN Resound. The authors also wish to thank the participants in this study; Dianna Gould, Hannah Bannon, and Kathleen Lea from Auburn University; Marianne Hawkins, Paula Folkeard, Sarah Harper, Linh Nguyen Vaccarello, Frances Richert, Christine Meston, and Christine Brown from Western University; and Alice Cellino at Columbus Speech and Hearing Clinic in Columbus, Georgia, for their efforts with data collection.

\section{References}

1 American Academy of Audiology (AAA). American Academy of Audiology Clinical Practice Guidelines on Pediatric Amplification. 2013. http:// www.audiology.org/publications-resources/document-library/ pediatric-rehabilitation-hearing-aids. Accessed July 9, 2016

2 Audioscan. Verifit ${ }^{\circ}$ User's Guide 4.2. 2015. https://docs.audioscan. com/userguides/archive/Verifit2UsersGuide4.2.pdf. Accessed August 5,2019

3 Bagatto MP, Moodie S, Scollie S, Seewald R, Moodie S, Pumford J, Liu R. Clinical protocols for hearing instrument fitting in the desired sensation level method. Trends Amp 2005;9(04):199-226

4 Bagatto MP, Scollie SD, Seewald RC, Moodie KS, Hoover BM. Realear-to-coupler difference predictions as a function of age for two coupling procedures. J Am Acad Audiol 2002;13(08):407-415

5 Bagatto MP, Scollie SD, Hyde M, Seewald R. Protocol for the provision of amplification within the Ontario infant hearing program. Int J Audiol 2010;49(Suppl 1):S70-S79

6 Bagatto MP, Seewald RC, Scollie SD, Tharpe AM. Evaluation of a probe-tube insertion technique for measuring the realear-tocoupler difference (RECD) in young infants. J Am Acad Audiol 2006;17(08):573-581

7 Bingham K, Jenstad LM, Shahnaz N. Longitudinal changes in realear to coupler difference measurements in infants. J Am Acad Audiol 2009;20(09):558-568
8 Blumsack J, Clark-Lewis S, Ross M. Comparing RECD norms to measured values in undernourished children. 2011. Poster Presentation at the 23rd Annual Meeting of the American Academy of Audiology, Chicago, IL, April 8, 2011

9 Blumsack JT, Clark-Lewis S, Watts KM, Wilson MW, Ross ME, Soles L, Ennis C. Alternative metrics for real-ear-to-coupler difference average values in children. J Am Acad Audiol 2014;25(09): 823-833

10 Cohen J. Statistical Power Analysis for the Behavioral Sciences. Hillsdale, NJ: Lawrence Erlbaum Associates; 1988

11 Centers for Disease Control and Prevention. Measuring Head Circumference. 2016. https://stacks.cdc.gov/view/cdc/38538. Accessed April 1, 2018

12 de Onis M, Frongillo EA, Blossner M. Prevalence and trends of stunting among-pre-school children 1990-2020. Pub Health Nutr 2011;15(01):142-148

13 de Onis M, Onyango AW, Van den Broeck J, Chumlea WC, Martorell RM. Measurement and standardization protocols for anthropometry used in the construction of a new international growth reference. Food Nutr Bull 2004;25(01):S27-S36

14 Feigin JA, Kopun JG, Stelmachowicz PG, Gorga MP. Probetube microphone measures of ear-canal sound pressure levels in infants and children. Ear Hear 1989;10(04):254-258

15 Joint Committee on Infant Hearing. Year 2007 Position Statement: Principles and Guidelines for Early Hearing Detection and Intervention Programs. 2007. http://pediatrics.aappublications.org/content/120/4/898.full?ijkey5oj9BAleq210lA\&keytype5ref\&siteid5aapjournals. Accessed February 2, 2018

16 Margolis RH, Bass-Ringdahl S, Hanks WD, Holte L, Zapala DA. Tympanometry in newborn infants $-1 \mathrm{kHz}$ norms. J Am Acad Audiol 2003;14(07):383-392

17 Martin HC, Munro KJ, Langer DH. Real-ear to coupler differences in children with grommets. Br J Audiol 1997;31(01): 63-69

18 McCreery RW, Walker EA, Spratford M, Bentler R, Holte L, Roush P, Oleson J, Van Buren J, Moeller MP. Longitudinal predictors of aided speech audibility in infants and children. Ear Hear 2015;36(01): 24S-37S

19 McCreery RW, Bentler RA, Roush PA. Characteristics of hearing aid fitting in infants and young children. Ear Hear 2013;34(06): 701-710

20 Moodie S, Pietrobon J, Rall E, Lindley G, Eiten L, Gordey D, Davidson L, Moodie K, Bagatto M, Haluschak M, Folkeard P, Scollie $\mathrm{S}$. Using the real-ear-to-coupler difference within the American Academy of Audiology pediatric amplification guide-line: protocols for applying and predicting earmold RECDs. J Am Acad Audiol 2016;27(03):264-275

21 Moodie S, Rall E, Eiten L, Lindley G, Gordey D, Davidson L, Bagatto M, Scollie S. Pediatric audiology in North America: current clinical practice and how it relates to the American Academy of Audiology pediatric guideline. J Am Acad Audiol 2016;27(03):166-187

22 Nozza RJ, Bluestone CD, Kardatzke D, Bachman R. Towards the validation of aural acoustic immittance measures for diagnosis of middle ear effusion in children. Ear Hear 1992; $13: 442-453$

23 Nozza RJ, Bluestone CD, Kardatzke D, Bachman R. Identification of middle ear effusion by aural acoustic admittance and otoscopy. Ear Hear 1994;15:310-323

24 Roush J, Bryant K, Mundy M, Zeisel S, Roberts J. Developmental changes in static admittance and tympanometric width in infants and toddlers. J Am Acad Audiol 1995;6(04):334-338

25 Scollie S, Seewald R, Cornelisse L, Moodie S, Bagatto M, Laurnagaray D, Beaulac S, Pumford J. The Desired Sensation Level multistage input/output algorithm. Trends Amplif 2005;9(04): 159-197 
504 Head Circumference and RECD Watts et al.

\section{Appendix A: Immittance Procedures}

For participants $\leq$ to 6 months, use $1000 \mathrm{~Hz}$ probe tone.

Criteria for inclusion:

- Single peak or highest of two peaks

- Negative-tail compensated static admittance: $>0.6 \mathrm{mmhos}$ (Margolis et $\mathrm{al}^{16}$ )

For participants age $>6$ months up to and including 36 months, use $226 \mathrm{~Hz}$ probe tone. Criteria for inclusion:

- Peak compensated acoustic admittance: 0.2 to 0.7 mmhos (Roush et $\mathrm{al}^{24}$ )

- Tympanometric width: 102 to 204 daPa

For children aged $>36$ months, use $226 \mathrm{~Hz}$ probe tone.

Criteria for inclusion:

- Peak compensated acoustic admittance: 0.4 to $1.4 \mathrm{mmhos}$ (Nozza et al ${ }^{22}$ )

- Tympanometric width: 60 to 168 daPa (Nozza et al $^{23}$ ) 


\section{Appendix B: Scatterplots with Trend lines}
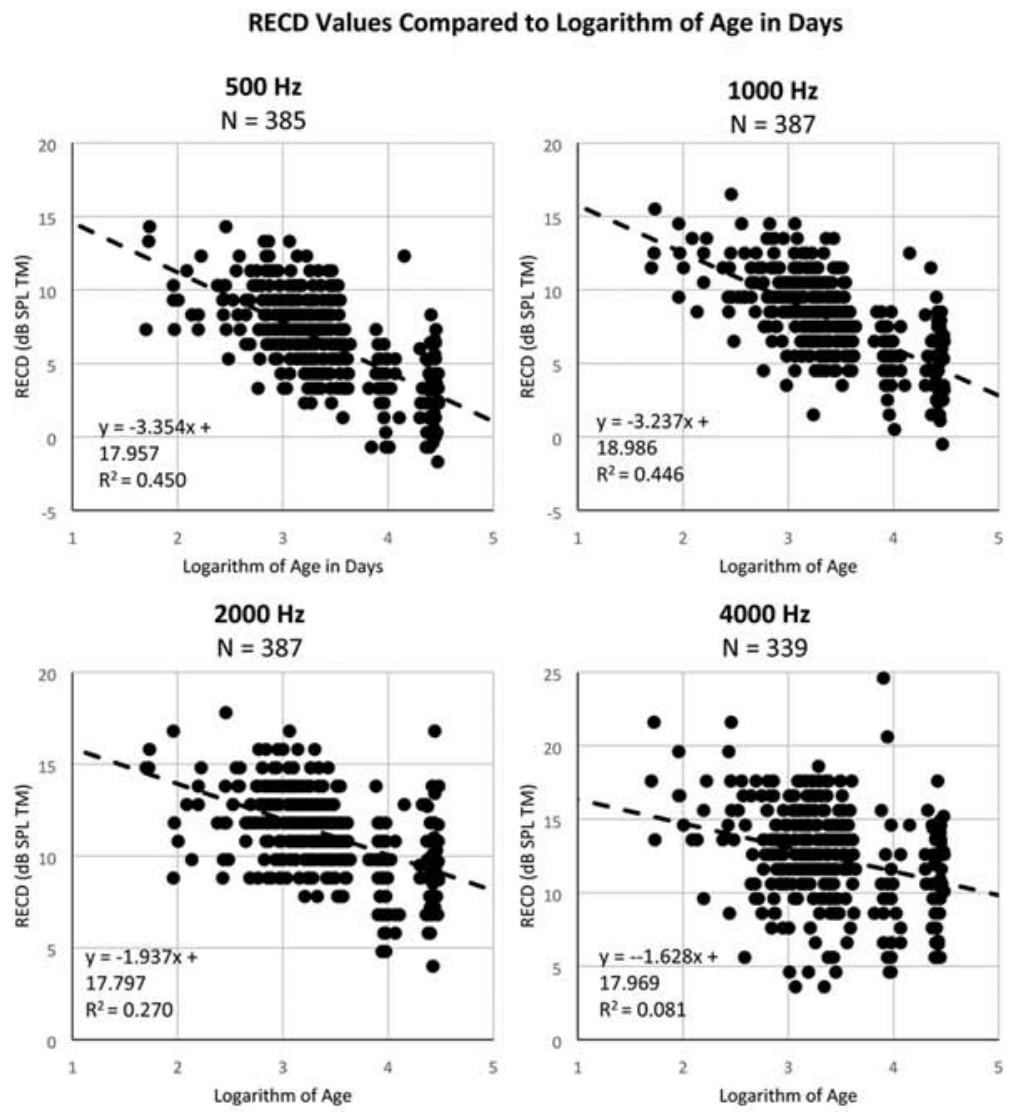

RECD Value Compared to Head Circumference
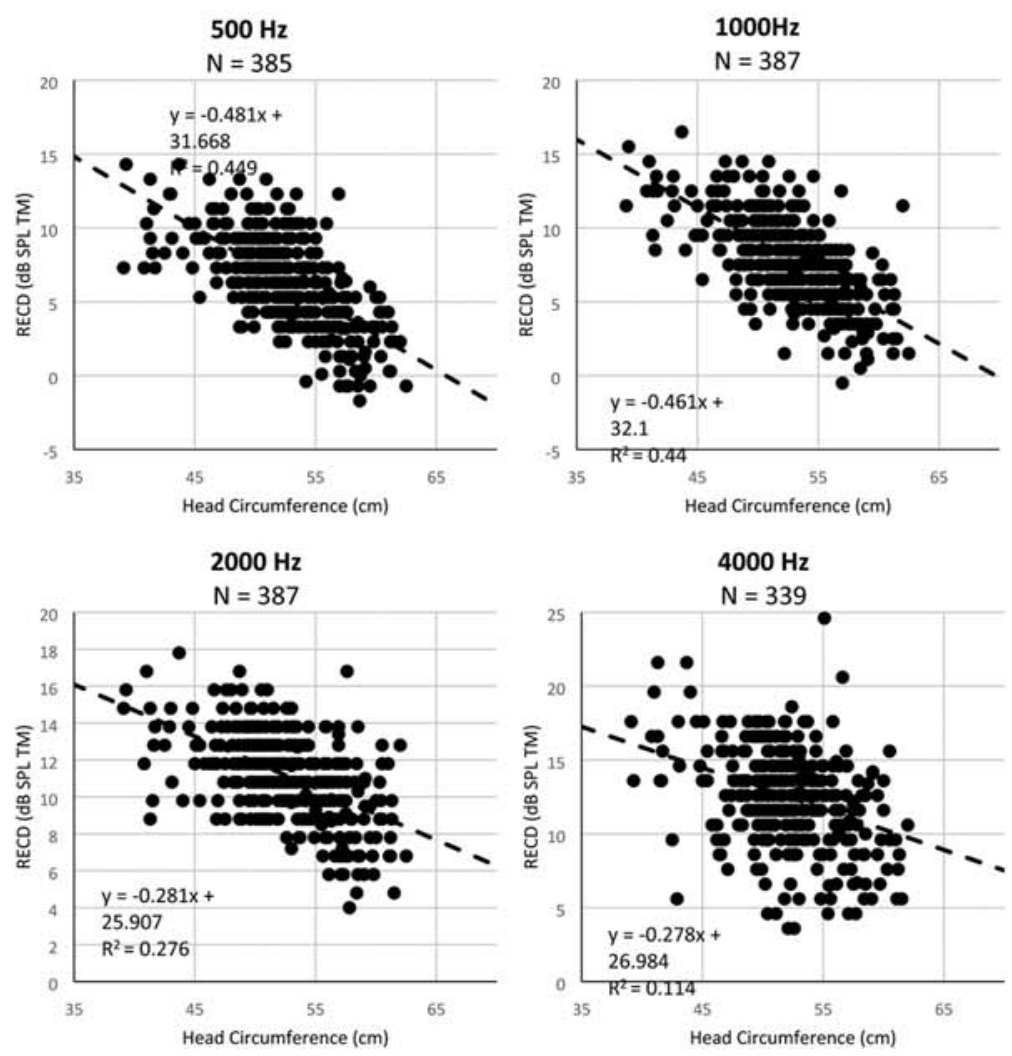